Correspondence

\section{A solution to the resource allocation debate? \\ SIR}

Problems of allocation of scarce resources in other fields are not new but their appearance on the medical scene makes their importance appear more urgent. This is probably for three reasons. Firstly medical technology is effective: patients with renal failure will die unless their blood chemistry is corrected, but if it is corrected they are likely to survive. Secondly medical technology is expensive: the more effective innovations require substantial and continuing financial support (the major part of this is still in the area of wages, the most costly part of the health service bill). Thirdly the inter-relationships of living standards in our society means that allocating finance for one area is clearly seen to take it away from another.

Against this background one reads the recent paper by Parsons and Lock, and the related editorial, in the fournal of medical ethics (I), and the letter responding to these by Dr Michael Kaye (2) who urges political action to ensure sufficient resources for dialysis. Renal dialysis often evokes interest by ethicists and in particular those who attempt to study resource allocation. It is the 'microenvironment' of resource allocation. It is where the 'buck stops'. A decision must be made for the individual patient who presents. It appears to be less dramatic than the heart transplant but is none the less pressing. As Parsons and Lock state the number of patients presenting is limited. The demand is finite. The technology is available. It is difficult not to agree with them that the main ethical problem is whether the profession should continue to keep quiet in collusion with the administrators and simply ration treatment in direct proportion to the resources made available, or whether more and more it should advertise its predicament. Of course this has its own problems. The nephrologist is not alone in pressing for more funds and for the allocation of resources which are scarce. The obstetrician would say more funds would enable him to give better service to the many women who do not seek his help until it is too late, perhaps by organising better service in the community. The cardiologist would say more money for research could reduce the premature death rate from ischaemic heart disease. How is the public to decide? The answer is simple. The general public does not and never will decide. Organised pressure groups will fight for particular areas of their interest. At the political levels ministers will only respond to massive public pressure, and usually in an illogical and short term manner. An unfortunate outbreak of smallpox brought an inquiry, questions in the House, guidelines and much publicity. The outbreak involved at most ten patients or possible patients. Diseases and deaths related to smoking are numerous and well documented. There is no public outcry. There is no special inquiry, few questions are asked in the House and the guidelines appear as inadequate warnings on cigarette packets. Recently proposed changes are paltry and do little to retrieve the situation.

Certainly it is only with debate and wider discussion that interest in health matters can be stimulated. The public as future or potential patients should be made aware of the implications of spending more on defence and less on health.

It would appear that we are in the midst of a revolution as profound as the agricultural and industrial. Men have to work less to stay alive. Less of our time is spent at our place of work and it appears that this can only get even shorter. New life styles must be evolved. The quiet epidemic of senility means that more and more of our population will be over 65 years of age and increasingly over 75 years. More of our work force will have to be redirected from industry which is not profitable and only maintained artificially into caring for others. As the caring business is under the pressures it follows it must be increased. Until the revolution stabilises and new priorities apper. we will be left in these predicaments of resource allocation.

The sadness of the Parsons and Lock paper is that what we, doctors, would like to predict as the seemingly logical answer to the problem, just does not wort. If doctors who are daily dealing with these problems cannot corne to a consensus is there any hope of administrators, politicians and pressure groups from varied back grounds coming to a simifor consensus ? Several authors have co sidered a lottery for patient selection. There certainly are good reasons to accept that each person has an equeg worth and if not, doctors shoule be the last in society to assume - the role of assigning value to one pessin and not to another. The lottery system implies that all are equal and at least deserve an equal chance क्f success from any life-saving trea ment that on technical grounds of $\overrightarrow{f e}$ would expect them to benefit from. The more one studies allocation of resources the more one is cotfused. The closer one gets to solution the further away it appears. This may well be because there is go solution. There are too many variables. What we have to do is find solutions that at least embody principles that we hold true and which do not sacrifice other prifciples. The duty to care and the duty to be fair seem to be of paramour importance in this area. The antithesis of this seems to be cost benefit analysis. This is an appro priate technique for arranging trip to the United States or Austrake but appears obscene when applied to decisions regarding other human lives. It has of course been dons. Builders will calculate the cost putting up scaffolding to repair the facade of a building against the possible cost of using a man in a chat on a rope, given a probability valife that he may fall and be injured or 
killed. It seems to me doctors should not involve themselves in this type of process.

Parsons and Lock's paper confirms with factual data what, in retrospect the profession thinks about such matters. It is not appropriate for them to draw up criteria for treatment or rejection of patients who may benefit from dialysis. The line of action seems to be clear. A lottery system offers equal chance to those we have to care for. The responsibility however to make society aware of this is grave. We must let the pressure groups, politicians and administrators know what we are doing and why. It is up to them to provide resources for our patients. It is for them to distinguish between the value of building a new road and the value of saving lives. The doctor should have nothing to do with it. The sooner we act in this way the closer we will approach the end of the revolution that is taking place. The longer the conspiracy of patching up and covering the cracks goes on the longer serious decisions about our society and the way it is run will be put off. This will generate serious problems and solutions which are not ideal will be forced upon us. The disquiet expressed by Parsons and Lock is real. The more doctors that express it and the sooner they do so in their individual fields the sooner we may reach a consensus.

\section{References}

(I) Parsons V, Lock P. Focus: Triage and the patient with renal failure. Fournal of medical ethics 1980; 6: 173-176.

(2) Kaye M. Correspondence. Fournal of medical ethics $198 \mathrm{I}$; 7 : I I I

\section{BRIAN POTTER Registrar \\ Renal Unit Royal Infirmary Edinburgh}

\section{Dr C J Brackenridge}

\section{SIR}

We have received today (II May I98I)* copies of Volume 7 Number I of your journal. It is with regret that we write to let you know that Dr Brackenridge died in November last year. As I am sure you would agree his death is a loss to the academic world and also the scientific one. It is just a pity he will not be able to comment on some of your readers' responses to his article (I).

\section{Reference}

(I) Brackenridge C J. Ethical aspects of plans to combat Huntington's chorea. Fournal of medical ethics I98I; 7: 24-27.

BRIAN DAVIES

Department of Psychiatry

University of Melbourne

Royal Melbourne Hospital

Victoria 3050

Australia

*Editor's parenthesis. We regret that we received this letter too late for our June issue, but appreciate being able to publish this tribute even though it is somewhat belated.

\section{Ill-disguised animus- a dispiriting review}

SIR

Professor Downie's review (in your June $198 \mathrm{I}$ issue) of the three papers on 'Prolongation of Life' published by The Linacre Centre is dispiriting. It is difficult to know whether it is worth responding to a writer from whom one had reason to expect philosophical criticism but who in the event indulges in an ill-disguised exhibition of animus. However, in the interests of proper standards in public debate and out of respect for the pretensions of your journal, if not the performance of your editorial colleague, I should like to make the following observations.

Downie claims to find two major pieces of inconsistency within the arguments of the three papers. The first is an inconsistency alleged to hold between, on the one hand, characterising the human life which commands our respect in terms of 'a capacity for human flourishing' and, on the other hand, adversely criticising those (like Lorber) who believe it possible to distinguish between lives which are and lives which are not worth living. In order to see that there is no inconsistency here it is important to bear in mind the distinction between a capacity and the exercise of that capacity. There is no obvious inconsistency in holding that someone gravely impaired in the exercise of a capacity is just as worthy of respect as someone who enjoys a richly developed exercise of that capacity - if what commands one's respect is precisely possession of the capacity. Since the radical capacity referred to in Paper $I$ was 'mind' (a 'second-order' capacity in Kenny's useful terminology) and since there must be a presumption that any member of the human (biological) species possesses this capacity, then reference to this capacity is in no clear way inconsistent with holding that every human being is of equal value.

The second inconsistency alleged is between the anti-consequentialism of the papers (especially Paper I) and Paper 3's lapse into 'utilitarianism' in the discussion of clincal cases. In particular, decisions to withhold or withdraw treatment on the grounds that the treatment would be burdensome are said to be utilitarian in character.

Now 'utilitarian' is a protean term so that Downie needs to attend to the way the papers characterise the utilitarianism to which they take exception. Paper I (p 6) argued against any form of consequentialism which must assume the commensurability of basic goods, claiming that this was an assumption which could not be soundly made. Is one involved in making this kind of assumption in raising and answering the questions which Paper 3 takes to be relevant to decisions to withdraw or withhold treatment? Those questions are: is treatment futile? is the risk/benefit ratio of treatment unacceptable? does the benefit to be expected from treatment justify the burdens - physical, psychological or financial - which treatment will involve? It is not necessary in answering these questions to make covert assumptions about the commensurability of basic goods or, in particular, about the possibility of measuring the value of a human life. These questions are discussed in the Roman Catholic moral tradition within the controlling assumptions that there are limits to duty in respect of care for one's own life and health; that some activities are supererogatory; and that the socalled doctrine of the sanctity of life is primarily negative in its import (absolutely forbidding the intentional killing of the innocent).

One would not guess from Downie's final paragraph that Paper I presents a rationale for the existence of certain absolute prohibitions by reference to the idea of openness to the basic goods which are constitutive of human flourishing: anything which amounts to treating any of these goods as instrumental is a failure in openness. A critique of this line of thought might have been instructive. But Downie writes as if the papers gratuitously invoke absolute prohibitions on killing (in fact, the relevant prohibition is on 